\title{
Mechanisms Explaining Variety Naming by Farmers and Name Consistency of Rice Varieties in The Gambia ${ }^{1}$
}

\author{
Edwin Nuijten* and Conny J. M. Almekinders \\ Technology and Agrarian Development Group, Wageningen University, Hollandseweg 1, 6706 KN, \\ Wageningen, The Netherlands \\ *Corresponding author; e-mail: edwin.nuijten@wur.nl
}

\begin{abstract}
Mechanisms Explaining Variety Naming by Farmers and Name Consistency of Rice Varieties in The Gambia. Understanding variety naming by farmers is important for better understanding crop genetic diversity in farmer fields and its management by farmers. This paper describes variety naming of rice by farmers in The Gambia and presents mechanisms that explain naming diversity and consistency. Three types of variety names can be distinguished, referring to common old varieties, common new varieties, and uncommon varieties. Interview and plant data suggest that variety exchange affects variety naming within villages. As a result, variety names give information on the period of time a variety is used in a village, and on the flow of varieties between and within villages. Name consistency within and between villages results from and illuminates the dynamics of variety exchange within and between villages.
\end{abstract}

Key Words: Variety naming, name consistency, farmer management, rice, The Gambia.

\section{Introduction}

In countries without well-functioning formal seed systems, farmers exchange seed in various ways: through family ties, friendships, and trade and labor relations. Seed exchange occurs within and between villages, sometimes over large distances. Distances over $1,000 \mathrm{~km}$ are reported in Ethiopia (McGuire 2005). In principle, for farmers to obtain or exchange seeds of the right variety, consistent variety naming is important, as the visible traits of seeds only reveal a small portion of the varietal properties. Some studies reported consistency in variety naming, e.g., on sorghum (Sorghum vulgare L.) in Ethiopia (Teshome et al. 1997; Tunstall et al. 2001), and on maize (Zea Mays L.) in Cuzalapa, Mexico (Louette et al. 1997). However, other studies found less consistent naming, e.g., on maize in Oaxaca, Mexico (Badstue et al. 2002), on cassava (Manihot esculentum Crantz) in the Peruvian upper Amazon (Salick et al. 1997), and on rice

\footnotetext{
${ }^{1}$ Received 28 June 2007; accepted 15 April 2008; published online 24 June 2008.
}

in Lao PDR (Oryza sativa L.) (Appo Rao et al. 2002). The combined information from these studies suggests that the level of consistency in variety naming in a farming system is variable and influenced by various socioeconomic factors, such as markets and infrastructure, and agroecological factors, such predictability of rainfall and proximity of different ecologies. Ethnobiological studies described in detail folk classification and naming of plant species and concluded they were remarkably consistent (Berlin et al.1973; Berlin 1992). The explanation is that, independent from culture, humans share a common understanding how to classify the natural environment (Boster 1987; Berlin 1999). But so far, little attention has been paid to crop variety naming that relates to the level below species in biological classification systems.

To study consistency in variety naming, the logical starting point is the character of variety names. Various researchers reported for a range of crops in different parts of the world that farmers name their crop varieties after plant traits or for the person who introduced or first encountered the variety. This, for example, is the case for rice 
in Sierra Leone (Richards 1995), for beans (Phaseolis spp.) in Central America (Almekinders, personal observation) and Malawi (Martin and Adams 1987), and for sweet potato (Ipomoea batatas L.) in Irian Jaya (Schneider et al. 1993). Predominantly inflorescence-related traits are used in naming sorghum varieties in Ethiopia (Teshome et al. 1997), but also variety names that refer to place of origin are found (McGuire 2005). Mostly agronomic and morphological traits are used to name varieties of rice in Malaysia, Thailand, Nepal, and Lao PDR (Lambert 1985; Dennis 1988; Bajracharya et al. 2006; Appa Rao et al. 2002). These studies pay little attention to possible mechanisms of naming, i.e., how the dynamics of variety naming are shaped by time scales and consistencies within and between villages.

If such mechanisms exist and are understood, they could support the understanding of the dynamics in variety exchange and farmer management of genetic diversity. This in turn can contribute to improving farmer seed systems and make variety introductions by national agricultural research institutes and NGOs more effective. Understanding variety naming by farmers facilitates and improves the accuracy of the estimation of crop and genetic diversity in farmer communities and in farmer fields (see Quiros et al.1990). This article provides information on rice variety naming from a case study in The Gambia. To understand how the breeding system influences variety naming, the information on rice variety naming was compared with information on pearl millet (Pennisetum glaucum [L.] R. $\mathrm{Br}$.), which, in contrast to rice, is a crosspollinating crop.

\section{Materials and Methods}

Semistructured interviews in four villages (Tujereng, Kitti, Faraba, and Janack) in 2000 provided detailed information on the naming of rice varieties in combination with information on variety use and management, selection practices, and crop husbandry. Because the first author lived in Tujereng for two years, the information from this village is most detailed. At harvest, rice seed samples were collected from farmers for morphological and molecular analyses (see Nuijten and Van Treuren 2007). Later, in 2002, a questionnaire was administered in 10 villages (Fig. 1) which provided data on number of varieties grown, cultivated area, seed loss, seed distribution, seed sources, and variety names. In conjunction with this questionnaire, farmers were asked for seed samples. As many rice samples as possible were collected (in total 297). The number of samples provided per farmer varied from zero to five. Some women suffered bad harvests and could not give any samples. Other interviewees did not have the key to the rice store, stored their seed in places difficult to reach, or were reluctant to give seed. Primarily, the collected samples were meant to check on variety names given and their consistency.

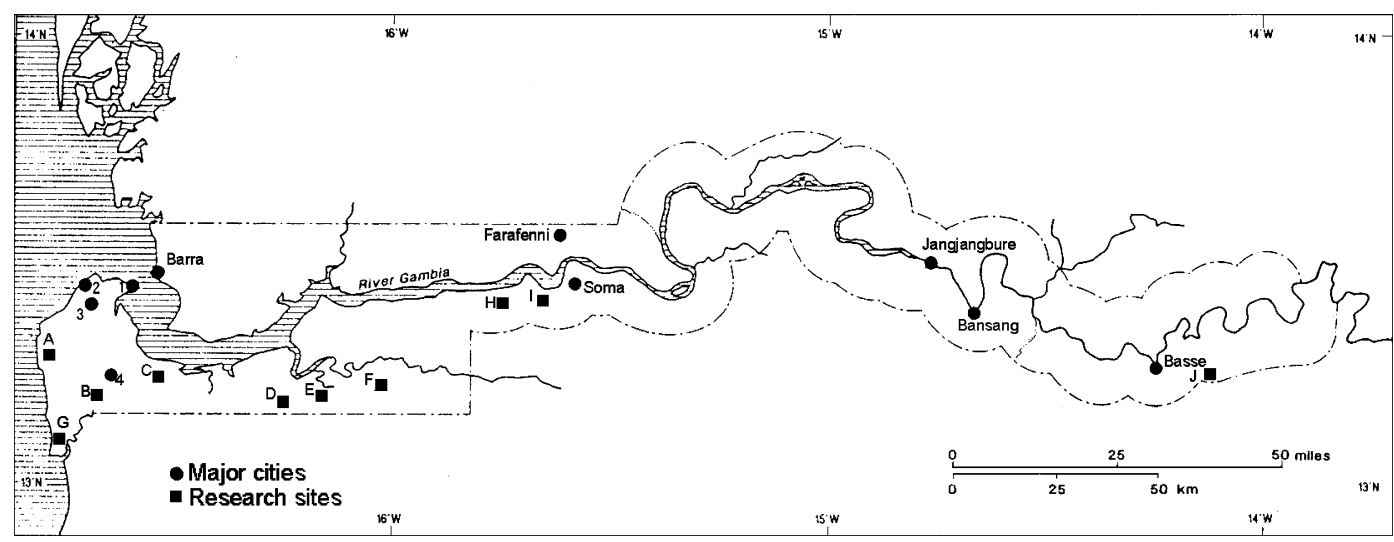

Fig. 1. Research sites: A: Tujereng, B: Kitti, C: Faraba, D: Janack, E: Batabut Kantore, F: Sangajor, G: Kartong, H: Jiroff, I: Massembe and J: Sanending. Major cities: 1: Banjul (Capital), 2: Bakau, 3: Serrekunda, 4: Brikama. 
The 10 panicles per rice seed samples were sufficient for morphological comparison among varieties because of limited intravarietal variation. First, the samples (in total 177) from Tujereng, Kitti, Faraba, and Janack were compared and visually grouped by the researcher on the basis of husk color, husk shape, seed size, awn length, and awn color. Those samples for which similarity with other samples was unclear were sown in two single-replication trials (one for short-duration varieties and one for long-duration varieties) to observe differences in plant height, time of flowering, basal leaf color, tillering habit, and leaf angle. Upon observation, they were classified either as similar or distinct. Of these samples, one voucher specimen per distinct variety was maintained. Visual evaluation (including seed measurements) of the samples from the other villages (in total 120) was completed after the rainy season of 2002 .

Initially, the analytic approach was to cluster villages into several regional units based on the proximity of the villages. But when it appeared that villages within regional units showed distinct differences in terms of variety naming, it was decided to analyze and compare the data between villages instead of between regional units. The village as research unit also allows comparing intra- and inter-village dynamics.

\section{Results}

\section{How Varieties Get Their Names}

Based on semistructured interviews with (female) rice farmers, many different ways of naming rice varieties became evident. The following were documented:

- The name refers to a particular morphological characteristic, like husk color, plant height, presence of awns, grain size, or grain shape.

- The name refers to agronomic traits like growth duration or the capability to suppress weeds.

- The name is used to label culinary traits like taste.

- A variety is named after the woman farmer, extension officer, or organization from which a farmer acquired it.

- A variety is named after the village or region from which a farmer acquired it.
- In rare cases, rice varieties are named after animal traits (Mani Konsonkuto refers to the bottom of a female baboon).

- Women sometimes pick out a different specimen from an already known variety and call the new variety Tombon Mano (selected rice).

- A variety is given the same name as a variety it resembles in a particular characteristic.

- In the case of modern varieties, the name is often modified to make pronunciation and remembrance easier. For example, Terwiet probably refers to the formal variety $I R$ 8 when pronounced in French (Suso, personal communication).

\section{Multiple Names for One Variety and Multiple Varieties with One Name}

The study showed that a variety can have different names and different varieties can share the same name, even in the same village. One reason for varieties sharing the same name can be, as indicated, because they share a particular characteristic, like, for example, Mani Koyo (white rice), which refers to the straw husk color. Other examples from the study illustrate how different varieties can end up with the same name or how one variety gets several names:

- As a reaction to the decrease in rainfall in the 1970s, the Soil and Water Management Department (SWMD) of the Gambian government started building dykes and dams in the lowlands in order to extend the area and season for rice cultivation. At the same time, SWMD introduced several modern varieties. All these varieties were often called Baras by farmers. Baras is supposedly derived from the Portuguese word for dyke. One woman explained that in their village three varieties have the name Baras. This can be explained by the fact that after the construction of the dykes, SWMD usually distributed three types of varieties, of short, medium, and long duration.

- The variety Binta Sambou was selected as an offtype by a woman in Tujereng called Binta Sambou, and everybody in Tujereng now calls this variety Binta Sambou. The variety was 
taken to other places, like Kitti, where it is called Tujereng Mano, after the place from which they got it. From Kitti it was brought to other places, like Madina Silaam and Faraba, where women called it Mani Koyo because of the whitish husk. Another woman in Kitti calls a different variety Tujereng Mano, because it resembles in husk color and grain shape the original Tujereng Mano (Binta Sambou).

- After the introduction of the formal variety Peking in the late 1960s, other varieties were introduced with the same short stature, grain shape, and husk color as Peking. These varieties are also called Peking, or Mani Suntungo (short rice), or Chinese Mano (because Peking is thought to originate in China).

- A woman may change the name of a new variety several times until she finds a name she feels comfortable with. A women in Tujereng got a rice variety from a village called Jokadou on the north bank of the river Gambia and called it Jokadou Mano. The next year she called it Bali Mano, referring to Bali, the wider area around Jokadu. Another woman in Tujereng called a rice variety with small grain Mani Tereyengo (quick rice), but the year after that she changed the name to Badibu Mano, after the place of origin.

These examples make it clear that variety names can be confusing; within a village, different farmers use the same variety name to refer to different varieties and different names to refer to the same variety.

\section{VARIETY-NAMING DYNAMICS}

As exemplified above, at first sight there seems to be no system in variety naming. However, a

Table 1. VARIETy names, theIr MEANINGS, ORIGIN, AND YEAR OF INTRODUCTION OF UPLAND RICE VARIETIES SAMPLED IN TUJERENG (BASED ON INTERVIEWS DURING THE YEAR 2000 AND INFORMAL INTERVIEWS IN FOLLOWING YEARS).

\begin{tabular}{|c|c|c|c|c|}
\hline Variety name & Meaning of name & Origin & Year of introduction & Common variety \\
\hline Sefa Fingo & black husk & not known & old $^{1}$ & yes $^{5}$ \\
\hline Sefa Koyo & white husk & not known & old $^{1}$ & yes $^{5}$ \\
\hline Sefa Kusee & husk with ash color & Sefa Fingo? & old $^{1}$ & \\
\hline Sefa Nunfingo & white husk with black tip & Sefa Fingo? & old $^{1}$ & yes $^{5}$ \\
\hline Hombo Wulengo & red husk & not known & old $^{1}$ & yes $^{5}$ \\
\hline Kukur & big seed & not known & old $^{1}$ & yes $^{5}$ \\
\hline Bendou & swelling of seed & not known & old $^{1}$ & yes $^{5}$ \\
\hline Mani Tima & long awns & not known & old $^{1,2}$ & yes $^{5}$ \\
\hline Moti & early maturity & various places & $+/-1970$ & \\
\hline Mani Wulendingo & red husk and small seed & various places & $+/-1970$ & \\
\hline Kari Saba ${ }^{3}$ & matures in three month & various places & $+/-1970$ & yes \\
\hline Mani Mesengo & small seed & various places & ?? & \\
\hline Penkou Mano & name of woman & field of Sefa Koyo & $+/-1980^{4}$ & \\
\hline Banghura & name of extension officer & not known & $1982^{4}$ & \\
\hline Sonna Mano & name of woman & Jangoll, Casamance & $+/-1990$ & \\
\hline Binta Sambou & name of woman & field of Kari Saba & $+/-1992$ & yes \\
\hline Jokadou Mano & place of origin & Jokadou & 2000 & \\
\hline Foni Mano & place of origin & Foni & $2000^{4}$ & \\
\hline Sainy Kolly & name of woman & Casamance & $2000^{4}$ & \\
\hline Muso Noringo & dirty woman & ?? & $2000^{4}$ & \\
\hline Bonti & ?? & various places & $2001-2003^{4}$ & \\
\hline Fatou Demba Mano & name of woman & Tujereng & $2002^{4}$ & \\
\hline
\end{tabular}

\footnotetext{
${ }^{1}$ At least 40-50 years ago, variety was already in the village when the oldest generation was born.

${ }^{2}$ Was considered a lost variety by farmers in Tujereng.

${ }^{3}$ Previously known as Likunda Mano (referring to the woman who introduced the variety).

${ }^{4}$ Cultivation was stopped.

${ }^{5}$ Variety was common in the past.
} 


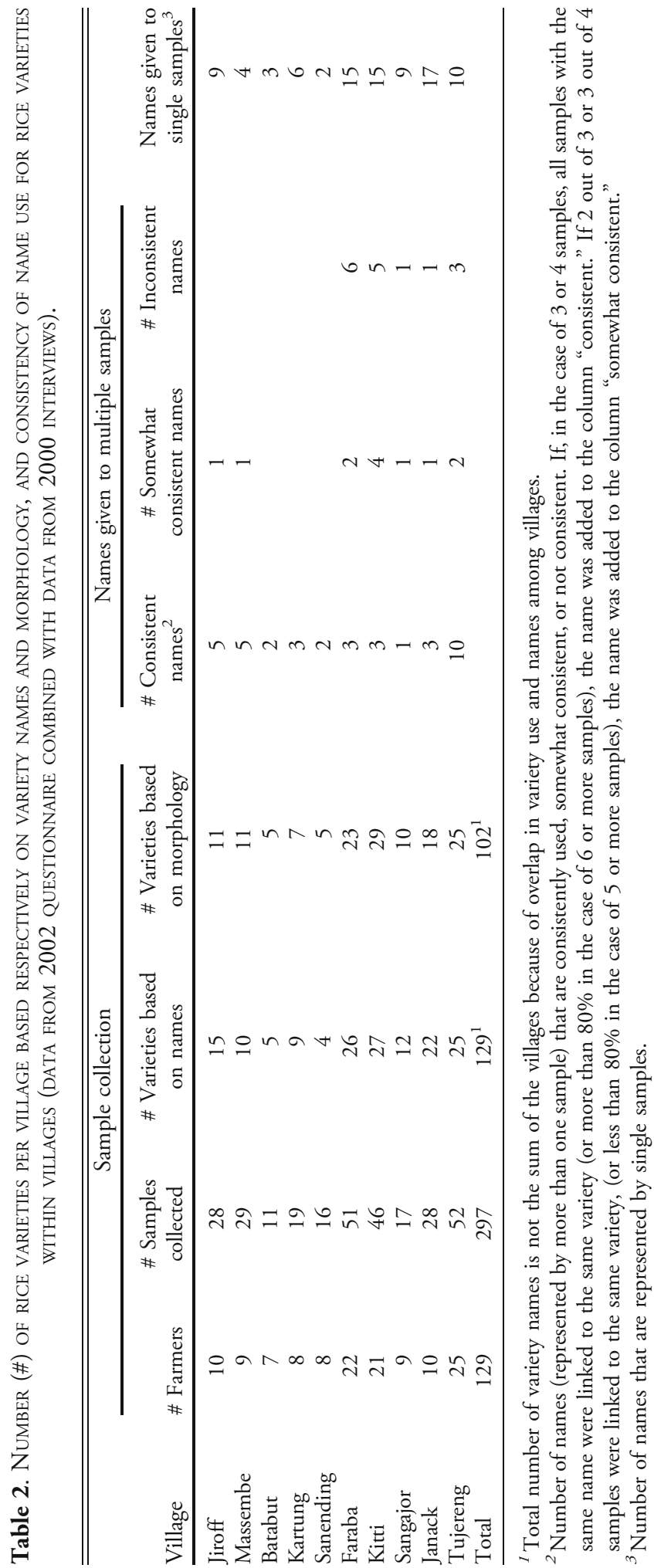




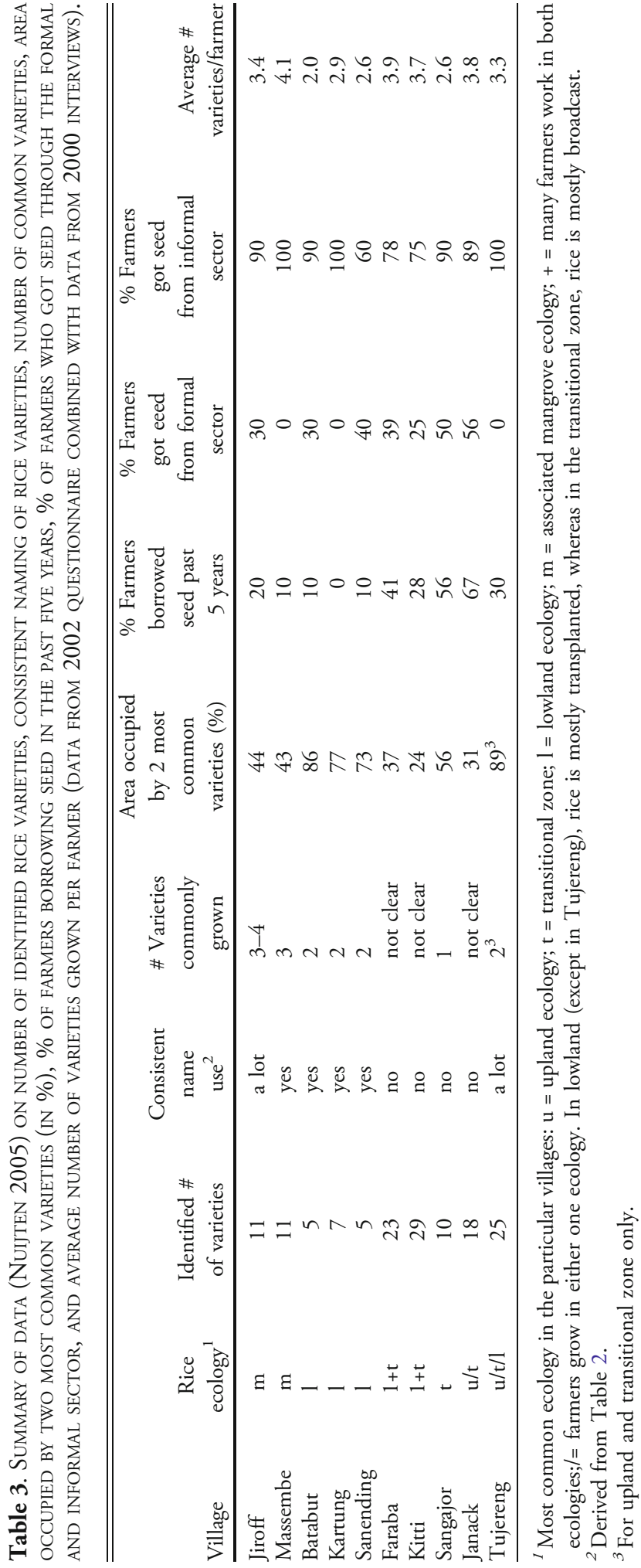


closer look reveals a logic related to the time the variety is in use in a community. In Tujereng, all old varieties (i.e., those used in the village for 40-50 years or more) refer to a morphological characteristic (Table 1). Sefa Koyo owes it name to its white husk color, Sefa Fingo to its blackish husk color, Hombo Wulengo to its red husk color, and Kukur to its large seed size. More recentlyintroduced varieties, like Binta Sambou and Sonna Mano, are named after the women who introduced or found these varieties. Also, the variety Kari Saba (meaning three months, the length of its maturity), which was introduced 30 years ago, was at first named after at least one woman. Several women claim they are responsible for the introduction of Kari Saba to Tujereng.

From these examples, we conclude that new rice varieties introduced into a village which are adopted by many other farmers of the same village in a short period of time are named after the person who found or brought the rice variety to the village. Naming a variety after the person who introduced it can be perceived as giving credit to that person. After a period of time, maybe 20 years or so, the variety gets a new name based on its distinctive morphological, agronomic, or culinary traits. Possibly, when varieties get more widely diffused, the actual origin loses its meaning and is forgotten. The fact that a few women call Binta Sambou "Mani Koyo" may illustrate such a case, in which the variety name is in the process of transformation from new to old rice. Completely new varieties introduced by farmers but not adopted by other farmers, like Jokadou Mano or Foni Mano, carry names of any sort, based on the cultivator's vagary. In regard to names, therefore, we can refer to old, new, and idiosyncratic forms.

\section{CONSISTEnCy IN VARIETy NAMING}

The samples collected during the interviews in 2000 and 2002 were compared in order to understand which varieties were more common, to what extent name-giving within villages was consistent, which varieties were grown in multiple villages, and to what extent the names of the same varieties grown in different villages were the same. Consistency of naming refers to the degree to which variety names that farmers attach to their seed lots indeed represent those varieties. Naming was considered consistent if more than $80 \%$ of the seed lots to which a particular name was attached represented the same variety.

\section{Consistency in Variety Naming within Villages}

Given an early observation during fieldwork that different farmers sometimes give different names to the same variety, the assumption was that the number of variety names given by farmers would be much higher than the number of identified varieties. The total number of varieties identified in this study on the basis of seed sample comparisons was 102 , which is $80 \%$ of the total number of variety names (129) (Table 2). However, the situation varied between villages. In Jiroff, for example, 11 varieties were identified, while 15 names were linked to these varieties. In Massembe, 11 varieties were identified and 10 names given (Table 2). Interestingly, some villages have a more consistent name use than other villages. Table 2 shows, per village, the number of names consistently used, the number of names that showed some consistency, and the number of names that were not consistently used.

Table 3 shows the relation between variety name consistency, variety use, and agroecological zone. It combines data from Table 2 with variables like common rice ecology, percentage of farmers who borrowed seed in the past five years, number of varieties commonly grown, and area occupied by the two most common varieties. The data indicate that variety naming is most consistent in those villages where farmers grow rice in the flooded lowlands. In Tujereng, where most farmers work in the uplands, variety naming is also quite consistent. Least consistent is variety naming in Sangajor and Janack, where farmers grow rice mostly in the transitional zone (intermediate between flooded lowlands and dry uplands). The number of entries for which only one name was linked to one sample was also the highest for Sangajor and Janack (Table 2). In Kitti and Faraba, where farmers grow rice both in flooded lowland and the transitional zone, variety naming is more consistent for varieties planted in the flooded lowlands than for those sown in the transitional zone.

In those villages that have consistent name use (Massembe, Batabut, Kartung, Sanending, and Tujereng), two or three varieties are known as the commonly-used varieties by almost all farmers (Table 3). For example, in Tujereng, it is 


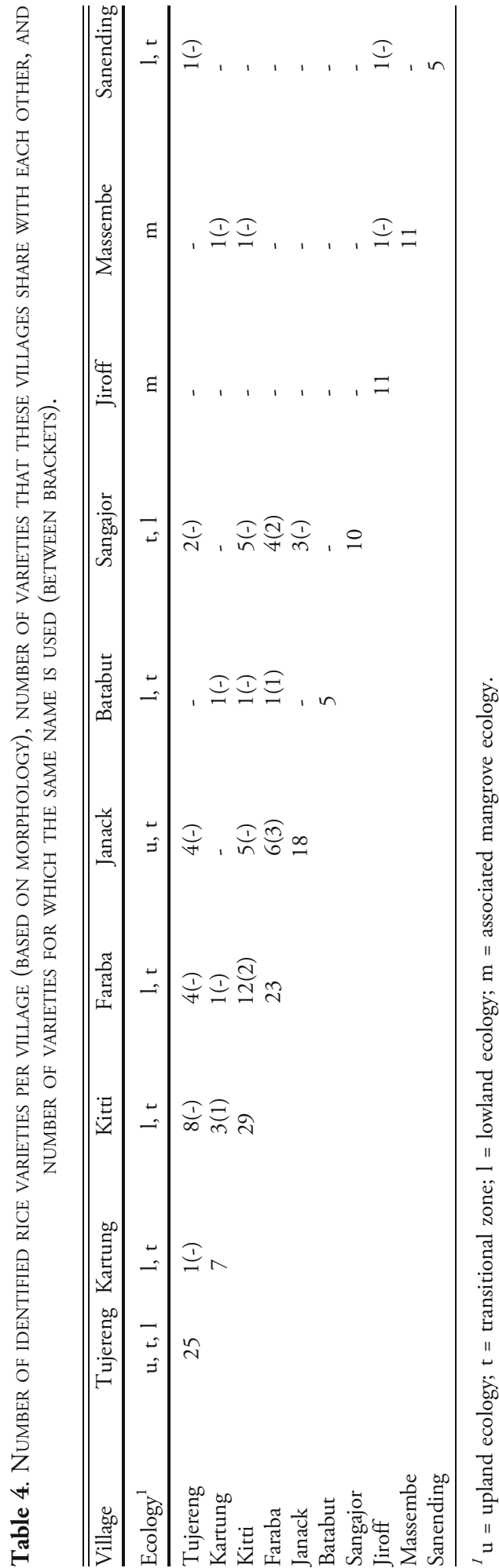

common knowledge that Binta Sambou and Kari Saba are the most widely used varieties in the uplands. In Jiroff, four varieties are more common, which seems to be related to small differences in variety use between the two nuclei Jiroff consists of. In contrast, in the other villages (Kitti, Faraba, Janack, and Sangajor), it is less clear which ones are the common varieties.

In those villages where variety naming is consistent, $10 \%$ or fewer of the farmers borrowed seed in the last five years. In the other villages, there is less consistency in variety naming, and farmers more frequently borrowed seed in the last five years (Table 3 ). The latter villages share the characteristic that farmers work in the upper sequence of the transitional zone. That part of the transitional zone is more drought prone than the lowlands and the uplands because it is often not flooded (unlike the lowlands) and it has a claylike texture (unlike the uplands), which decreases the water uptake by plants under drought conditions. Hence, in a village like Janack, where farmers suffer from bad harvests frequently ( $\mathrm{Ta}$ ble 3), it is likely to be more difficult for farmers to assess which varieties perform best. In Tujereng, where conditions are somewhat more favorable, the two common upland varieties were quickly adopted by farmers after their introduction. In recent years, farmers of Tujereng also experience bad harvests more often than previously.

Another factor that seems related to consistency of variety naming is the introduction of varieties by the formal sector (i.e., agricultural extension and NGOs), which is different from the introduction of varieties through the informal system (i.e., farmer-to-farmer exchange; no local seed trade exists for rice). If farmers adopt a new variety introduced by a particular farmer, i.e., through the informal system, it is normally only one variety at a time. If many farmers in a village adopt that variety in a short time span, all farmers will name the variety after this particular farmer. In such a case, the chances of name confusion are small. An NGO introducing several varieties into a village at the same time is likely to create name confusion, since the farmers cannot name all varieties after the person working for the NGO or the NGO itself. The situation in Faraba with three varieties that share the name Barass (referring to the dykes built by SWMD) represents such a case. In Kitti, at least two varieties share the name Worldbank. 


\section{Consistency in Variety Naming between Villages}

Whereas seed that farmers obtain within a village is mainly used to replace lost seed stocks, seed obtained from other villages is typically used for experimentation (Nuijten 2005). The hypothesis was confirmed that each village has a distinct set of variety names since it is common practice for farmers to rename varieties obtained from other villages. On average, based on morphological identification of seed samples, villages share $10 \%$ of their varieties with other villages, while less than $2 \%$ of the total share the same name in two or more villages (see the numbers between brackets in Table 4). In most cases, however, these shared names are general names, like Mani Suntungo, Mani Wulengo, Barass, and Ablie Mano, which can be attached to different varieties, and they are often used in an inconsistent way within villages. For example, Ablie Mano is used in four villages for three generally-known varieties.

Apart from the common practice of renaming varieties obtained outside the village, we hypothesize that another factor contributing to name inconsistency between villages is that the use of intra-village seed sources is more common and important than outside-village seed sources (see Nuijten 2005). Apparently, what matters most for farmers in terms of variety naming is that they understand each other within a village. The result is that, although villages are linked to variety sources in the outside world, mostly via marital ties, each village has its own set of varieties and its own set of names.

\section{Discussion}

\section{Mechanisms for Variety NAming}

Three groups of variety names for rice can be identified. Names of common, long-used rice varieties usually refer to plant traits. Names of commonly-used rice varieties which have been more recently introduced, i.e., less than 30 years ago, often refer to the person who introduced and spread the variety. There is a third group of rice varieties, with idiosyncratic names, which are both old and new varieties that are not widely used. This suggests that, within a village, names of varieties depend on the popularity and the number of years that varieties are cultivated. Therefore, variety names give information about the period of time varieties have been cultivated in a village. This implies that the percentage of varieties in a village named after people or place of origin not only gives information about important links and actors in the village seed system, but can also serve as an indication of the level of variety replacement.

From these dynamics of variety naming, we deduce a naming mechanism that works as follows. When somebody gives seed of a new variety to various people in a village (relatives, neighbors, or friends), who in turn distribute it to many others in the village, there is a high rate of diffusion of the variety. As Gambian villages are relatively small and everybody knows each other, the most logical way to refer to the variety is by the person who introduced it. A variety name referring to the name of the person who introduced it is also a sign of recognition for successfully introducing a new variety. After a period of 20-30 years, farmers are familiar with the variety, and this is reflected in a gradual transformation of the name into one that now refers to a plant characteristic (often a characteristic referring to the seed), but also may refer to a culinary or agronomic characteristic. The speed of this process varies, depending on how quickly farmers of a village forget the origin of a variety. The type of characteristic used in the naming depends on the contrasts in plant morphology with other common varieties. For a period of time, when the new and old names of a common variety coexist, farmers use both names. This process of cross-referencing avoids possible confusion about the identity of the variety. In the case of less common varieties, the mechanism unfolds in a similar way, but different names are more likely to occur.

The intensity of seed exchange between villages can explain consistency in variety names between villages. When there is limited inter-village seed exchange, a variety is likely to end up with different names in different villages. In the case of multiple seed exchanges of the same variety between two villages, for example because conditions are comparable or farmers procure seed from a particular village, that variety may obtain the same name in both villages. When many farmers of the same village are looking for suitable varieties to fit a particular environment (like in the village Janack or Sangajorr), and multiple varieties are introduced into a village and adopted within a short time period, the diffusion of several of these varieties may be limited. In such a case, 
the diffusion of information relating to the different seeds will also be less intensive. Specific information relating to the various new varieties can then easily be mixed up, with the result that one name can be linked to several varieties, and one variety may have several names at the same time.

\section{Millet versus Rice (Outbreeding versus Inbreeding Crops)}

While in The Gambia rice varieties are often named after people, millet varieties mostly have ecotype names (Nuijten 2005). This difference is related to the fact that rice varieties are plentiful and are replaced relatively frequently, while millet varieties are few and not often replaced. Because of the small number of available varieties, millet farmers use the ecotype names (which have become part of the language) for naming millet varieties, whereas ecotype names cannot be applied to rice, which has many distinct varieties per ecology.

This difference in naming can largely be explained by the difference in breeding system, which in turn is related to the rate of introduction of new varieties. Whereas rice is a self-pollinating crop, and rice varieties behave as lines and maintain their distinctness well, millet varieties behave like populations, because millet is a crosspollinating crop. A high cross-pollination rate results in fewer new varieties (Nuijten 2005). In the case of self-pollinating crops (like rice and beans), but also in the case of sorghum, new varieties are more easily developed and maintained from off-types. This can explain the fact that farmers generally have access to many varieties in self-pollinating crops (and vegetatively-propagated ones) and hence use variety names instead of ecotype names.

\section{Other Crops and Cases}

The mechanism we present seems applicable to other farming systems in which variety names were documented, although with small differences. Some variations are the following. In Polynesia, a study found that older yam varieties are named after plant traits, and newer ones carry the names of people (Raynor et al. 1992). The study also points out that the people who successfully introduce new varieties usually are allowed to name them. More than in The Gambia, in Lao PDR, rice varieties are named after animals, birds, fish, flowers, and fruits (Appa Rao et al. 2002), and in Irian Jaya sweet potato varieties often refer to animals (Schneider et al. 1993). A distinctive naming mechanism for cassava varieties is used by the Amuesha in the Peruvian upper Amazon: they name their varieties after their ancestors (Salick et al. 1997). The Amuesha believe that before the beginning of this world, cassava were people, and that at the end of this world, they will be people again. The names of their cassava stock are revealed after a person self-induces a trance by not sleeping and chewing coca for days (Salick et al. 1997). To our knowledge, this is the only study showing a clearly different variety-naming mechanism.

In comparison, the lack of dynamics and high level of consistency in generic naming found by Berlin et al. (1973) refers to plant species, not to varieties within species. The greater consistency at the species level can be explained by the fact that plant species are less frequently introduced and abandoned than are varieties of species. The names of plant species thereby become part of language (and culture). In contrast, the naming of crop varieties is more the result of contemporary, dynamic social processes during which seed, variety names, and other associated information is exchanged. The naming of millet varieties, as well as of maize, also a cross-pollinating crop, more closely resembles that used for plant-species naming than for rice varieties. For rice, this implies that farming systems in which rice variety names reflect animal or crop characteristics are likely to be relatively static in terms of variety use.

\section{Variety Name Consistency}

This study indicates that variety naming within villages is more consistent than between villages, which can be explained by the higher functionality of variety naming within a village. In The Gambia, seed flows are mainly confined to within-village exchanges, and seed exchanges between villages are less frequent (Nuijten 2005). At the same time, the inconsistency of variety names between villages indicates that information on seeds and varieties does not easily or automatically travel with the seed lots themselves. Possibly, if it is not necessary, farmers in different villages may not need to communicate 
with each other about varieties in order to be able to work with those varieties.

The information exchange between people on seed and varieties may be subject to other factors. The presence of well-developed infrastructure and markets, as, for example, described in the case of sorghum in Ethiopia (see Teshome et al. 1997; Tunstall et al. 2001), could be such a factor, implying more intensive interaction and information exchange among farmers from different places, and explaining greater name consistency. In Cuzalapa, Mexico, the existence of different growing seasons was associated with high name consistency (see Louette et al. 1997). The different growing seasons provided farmers with alternative sources of fresh seed and stimulated seed exchanges among different villages. Other researchers found that farmers' varying skills and motivation in learning variety names influence the consistency in variety naming (Quiros et al. 1990; Boster 1986). In Peru, the lack of consistency in cassava variety names between families can be attributed to some extent to the quite unique naming process of cassava varieties (where varieties are named after ancestors), but also to the geographical isolation of the families (Salick et al. 1997).

\section{IMPLICATIONS FOR RESEARCH AND DEVELOPMENT}

The understanding of variety-naming mechanisms and the consistency of variety names in use by farmers have relevance for research and development. Name consistency, as a result of variety introduction, variety adoption, and seed loss rates, not only illuminates dynamics in variety use and replacement at intra- and intercommunity level, but also seems to reflect social organization. In The Gambia, naming can be considered a by-product of the importance of creating and reinforcing relationships and social security. Likewise, in Aguarana society in Peru, exchange of cassava varieties seems to have more social than economic importance (Boster 1986). Social importance of seed does not necessarily mean frequent or widespread exchange of seeds. The introduction of new varieties by NGOs or formal institutions can therefore not automatically rely on farmer-to-farmer exchange beyond the village boundary, and may need village-based interventions depending on the characteristics of intra- and inter-village seed flows.

Despite the over- and underestimations in crop diversity in this and other studies, for example in the case of potato in the Andes (Quiros et al. 1990), counting the number of variety names through questionnaires produces useful first indications of crop varietal diversity, such as identifying areas with relevant levels of diversity. Combining these indications of varietal diversity with insights into the naming mechanisms and in-depth interviews or focus group discussions can produce effective impressions of the diversity and its dynamics.

Genetic analysis can yield more precise information on the actual number of varieties in a farming system and the diversity it represents, but loses relevance when done in isolation from anthropological insights on farming systems and variety naming. Anthropological insights into the variety-naming mechanisms of a crop, e.g., naming after persons or places, later replaced by variety traits, may serve as a tool to discriminate between recently introduced and "older" traditional varieties. Relating this information to the broader scope of this research, which showed that the group of "old" traditional rice varieties represented less genetic diversity than the group of relatively "new" traditional varieties (Nuijten and Van Treuren 2007), emphasizes the importance of integrating research methods that are biological (ranging from botany to genetics) and anthropological (qualitative and quantitative) to achieve a thorough understanding of traditional seed systems and management of crop genetic diversity.

\section{Conclusions}

The information on farmer variety names in rice in The Gambia and their dynamics suggests a variety-naming mechanism that can be explained by and also reflects farmers' intra- and intervillage exchange of seeds and associated information. Next to the variety names, the mechanism also explains consistency of variety names being used. Literature suggests that this mechanism may not be the only type of variety-naming system. However, we hypothesize that the described mechanism can be found in many other region in the world, and that understanding the way varieties are named can provide relevant information to researchers and development agents about 
the diversity in the seed system and the characteristics of related seed flows.

\section{Acknowledgments}

This research was financially supported by NWO-WOTRO grant W89-124. The authors thank the National Agricultural Research Institute of The Gambia, the field assistants, and all collaborating farmers (particularly those from Tujereng) for their support. The authors want to thank Paul Richards and two anonymous reviewers for their comments on earlier versions of the manuscript.

\section{Open Access}

This article is distributed under the terms of the Creative Commons Attribution Noncommercial License which permits any noncommercial use, distribution, and reproduction in any medium, provided the original author(s) and source are credited.

\section{Literature Cited}

Appa Rao, S., C. Bounphanousay, J. M. Schiller, A. P. Alcantara, and M. T. Jackson. 2002. Naming of Traditional Rice Varieties by Farmers in the Lao PDR. Genetic Resources and Crop Evolution 49:83-88.

Badstue, L. B., M. R. Bellon, X. Juárez, I. Manuel, and A. M. Solano. 2002. Social Relations and Seed Transactions among Small-Scale Maize Farmers in the Central Valleys of Oaxaca, Mexico. CIMMYT Economics Working Paper No. 02-02.

Bajracharya, J., K. A. Steele, D. I. Jarvis, B. R. Sthapit, and J. R. Witcombe. 2006. Rice Landrace Diversity in Nepal: Variability of Agro-morphological Traits and SSR Markers in Landraces from a High-Altitude Site. Field Crops Research 95:327-335.

Berlin, B. 1992. Ethnobiological Classification: Principles of Categorization of Plants and Animals in Traditional Societies. Princeton University Press, Princeton, New Jersey. . 1999. How a Folkbotanical System Can Be Both Natural and Comprehensive: One Maya Indian's View of the Plant World.
Pages 71-89 in D. L. Medin and S. Atran, eds., Folkbiology. MIT Press, Cambridge.

D. E. Breedlove, and P. H. Raven. 1973. General Principles of Classification and Nomenclature in Folk Biology. American Anthropologist 75(1):214-242.

Boster, J. 1986. Exchange of Varieties and Information between Aguarana Manioc Cultivators. American Anthropologist 88(2):428436.

1987. Agreement between Biological Classification Systems Is not Dependent on Cultural Transmission. American Anthropologist 89(4):914-920.

Dennis, J. V. 1988. Farmer Management of Rice Variety Diversity in Northern Thailand. Ph.D. Thesis, Cornell University.

Lambert, D. H. 1985. Swamp Rice Farming: The Indigenous Pahang Malay Agricultural System. Westview Press, London.

Louette, D., A. Charrier, and J. Berthaud. 1997. In Situ Conservation of Maize in Mexico: Genetic Diversity and Maize Seed Management in a Traditional Community. Economic Botany 51(1):20-38.

Martin, G. B. and M. W. Adams. 1987. Landraces of Phaseolis vulgaris (Fabaceae) in Northern Malawi. I. Regional Variation. Economic Botany 41(2):190-203.

McGuire, S. 2005. Getting Genes: Rethinking Seed System Analysis and Reform for Sorghum in Ethiopia. Ph.D. Thesis, Wageningen University, The Netherlands.

Nuijten, E. 2005. Farmer Management of Gene Flow: The Impact of Gender and Breeding System on Genetic Diversity and Crop Improvement in The Gambia. Ph.D. Thesis, Wageningen University, The Netherlands. and R. Van Treuren. 2007. Spatial and Temporal Dynamics in Genetic Diversity in Upland Rice and Late Millet in The Gambia. Genetic Resources and Crop Evolution 54:989-1009.

Quiros, C. F., S. Brush, D. S. Douches, K. S. Zimmerer, and G. Huestis. 1990. Biochemical and Folk Assessment of Variability of Andean Cultivated Potatoes. Economic Botany 44 (2):254-266.

Raynor, B., A. Lorens, and P. Jackson. 1992. Traditional Yam Cultivation on Pohnpei, 
Eastern Caroline Islands, Micronesia. Economic Botany 46(1):25-33.

Richards, P. 1995. The Versatility of the Poor: Indigenous Wetland Management Systems in Sierra Leone. Geojournal 35(2):197-203.

Salick, J., N. Cellinese, and S. Knapp. 1997. Indigenous Diversity of Cassava: Generation, Maintenance, Use and Loss among the Amuesha, Peruvian Upper Amazon. Economic Botany 51(1):6-19.

Schneider, J., C. A. Widyastuti, and M. Djazuli. 1993. Sweetpotato in the Baliem Valley Area, Irian Jaya. A Report on Collection and Study of Sweetpotato Germplasm. April-May 1993. Bogor: CIP/CRIFC/RTCRC.

Teshome, A., B. R. Baum, L. Fahrig, J. K. Torrance, and J. D. Lambert. 1997. Sorghum Landrace Variation and Classification in North Shewa and South Welo, Ethiopia. Euphytica 97:255-263.

Tunstall, V., A. Teshome, and J. K. Torrance. 2001. Distribution, Abundance and Risk of Loss of Sorghum Landraces in Four Communities in North Shewa and South Welo, Ethiopia. Genetic Resources and Crop Evolution 48:131-142. 